\title{
Management of osteoporosis in women with breast cancer
}

\author{
Charles L Shapiro*,1 \\ ${ }^{1}$ Division of Hematology/Oncology, Icahn School of Medicine at Mt Sinai New York, NY 10029, USA \\ *Author for correspondence: Charles.shapiro@mssm.edu
}

\section{Practice points}

- Osteoporosis is a complex genetic disease with some modifiable risk factors.

- Several breast cancer treatments decrease estrogen levels, which causes net bone resorption, leading some to experience osteoporosis and fragility fractures.

- Dual x-ray absorptiometry is the gold standard screening test for osteoporosis measuring bone mineral density in the lumbar spine, total hip and the femoral neck. The T-score is what is most important in assessing fracture risk.

- Women with breast cancer should receive 1000-1200 mg per day of calcium (including dietary sources) and 800-1000 IU per day of vitamin D3.

- Algorithms exist for starting anti-osteoporosis drugs, zoledronic acid, denosumab or oral bisphosphonates.

- Before starting an anti-osteoporosis drug, a dental screening exam is required. During the treatment with these drugs, routine dental cleanings and exams should occur.

The screening, prevention and treatment of osteoporosis are similar in women with or without breast cancer. Breast cancer treatments, such as aromatase inhibitors, chemotherapy-induced ovarian failure and gonadotropin-releasing hormone antagonists all decrease estrogen levels, which in turn causes net bone resorption and bone loss. Bone loss over time will be of sufficient magnitude to cause some women to experience fractures. Thus, osteoporosis is an equation; the peak bone mass achieved by age 30 years minus the age-related and menopausal bone loss. Women should have their bone density measured by dual $\mathrm{x}$-ray absorptiometry scans every 2 years. As clinically indicated, women should receive anti-osteoporosis drugs such as zoledronic acid, denosumab or oral bisphosphonates.

First draft submitted: 11 March 2020; Accepted for publication: 5 May 2020; Published online:

27 May 2020

Keywords: aromatase inhibitors $\bullet$ bone health $\bullet$ breast cancer $\bullet$ chemotherapy-induced ovarian failure $\bullet$ clinical trials • denosumab • genetics • osteoporosis • side effects • zoledronic acid

Personal cure [1], that is dying of something else and not breast cancer, characterizes the experience of the majority of women with invasive breast cancer. Therefore, awareness of screening and treating the late and long-term effects of breast cancer treatments are of paramount importance in maintaining health [2]. Breast cancer treatment such as aromatase inhibitors (AIs), chemotherapy-induced ovarian failure (CIOF) and gonadotropin-releasing hormone antagonists $(\mathrm{GnRH})$ antagonists or agonists, all result in bone loss that in some women is of sufficient magnitude to cause osteoporosis and fractures. Osteoporosis is highly relevant to the 25 million cancer survivors estimated to be in the USA by the year 2040, the majority of whom will be in their sixth, seventh and eighth decades [3].

\section{Normal bone regulation}

Healthy bone mass involves two levels of regulation (Figure 1) [4]. Systemic hormones (e.g., androgens, estrogens, calcitonin and parathyroid hormone), and the mechanical forces imposed by gravity is one level of regulation. The other level regulation is the dynamic balance between osteoblasts, derived from mesenchymal precursor cells and responsible for new bone formation, and osteoclasts derived from hematopoietic precursor cells, which are responsible for bone resorption. The balance between osteoblast and osteoclast function regulates new bone formation and resorption [4]. The receptor activator of nuclear factor- $\mathrm{K}$ B ligand (RANKL) and osteoprotegerin (also called osteoclastogenesis inhibitory factor), a member of the TNF receptor superfamily, are both produced by the 


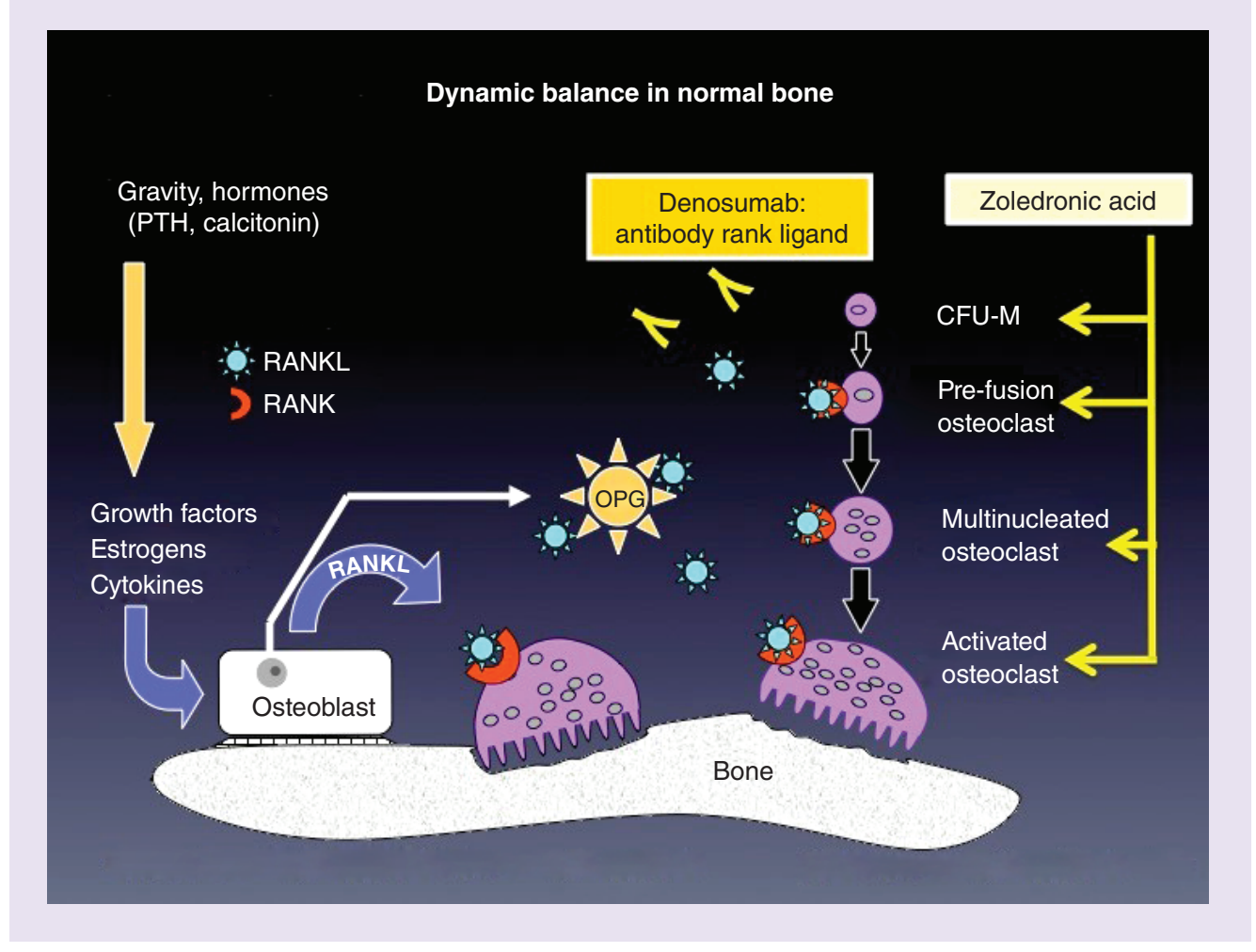

Figure 1. Dynamic balance in the bone remodeling unit; and the actions of the anti-resorption drugs, zoledronic acid and denosumab.

CFU-M: Colony forming unit macrophage.

Adapted from Nature [4].

osteoblast. When RANKL binds to RANKL receptor located on osteoclast precursor cells, it causes differentiation into mature osteoclasts and stimulates the multiple mechanisms by which bone resorption occurs. The osteoblast also secretes osteoprotegerin that acts as a decoy receptor for RANKL, thus reducing osteoclast activity. Also, the immune system regulates bone with $T$ cells playing a critical role in maintaining bone mass. The estrogen deficiency of menopause causes T cells to secrete TNF- $\alpha$ and RANKL that activate osteoclasts causing bone resorption [5,6].

In women, peak bone mass occurs around age 30 years. After 30 years, age-related bone loss in both women and men occurs. The magnitude of bone loss in women (relative to men) is higher due to menopause, where estrogen levels decrease by about 100-fold as compared with premenopausal women. Therefore, osteoporosis is an equation [7]: peak bone mass minus the loss of bone mass relating to aging and menopause. Although there are modifiable risk factors for osteoporosis (e.g., current smoking, in excess three alcoholic drinks per day), osteoporosis is primarily a genetic disease with the most important non-modifiable risk factors being aging, parental history of non-traumatic fracture, low body mass (or weight under 150 pounds) rheumatoid arthritis, chronic steroids for underlying conditions, and diabetes [8]. Healthy postmenopausal women will lose about $1 \%$ of their bone mineral density (BMD) in lumbar spine per year (Figure 2) [9].

\section{Genetics of osteoporosis}

Osteoporosis is a complex genetic disease. Recent studies using genome-wide association studies (GWAS) and GWAS meta-analysis show more than 200 to over 500 loci associated with bone mineral density, and many loci associated with fractures [10-12]. Several SNPs specifically associate with AI-induced bone loss and fractures [13], and response to AIs [14]. In postmenopausal women receiving AIs, single nucleotide polymorphisms (SNPs) in the ESR1, ESR2, CYP19A1 and CYP11A1 genes predicts decreases in bone density [15-17]. A case-cohort GWAS study shows that three SNPs in or near six genes located on chromosome 20 (CTSZ, SLMO2 and ATP5E), chromosome 6 (TRAM2 and TRAM14A) and chromosome 2 (MAP4K4) increase the fracture risks in women treated with AIs [13]. Ideally, a blood test of germ-line DNA would identify SNPs that predict a higher (or lower) risk of bone loss or 


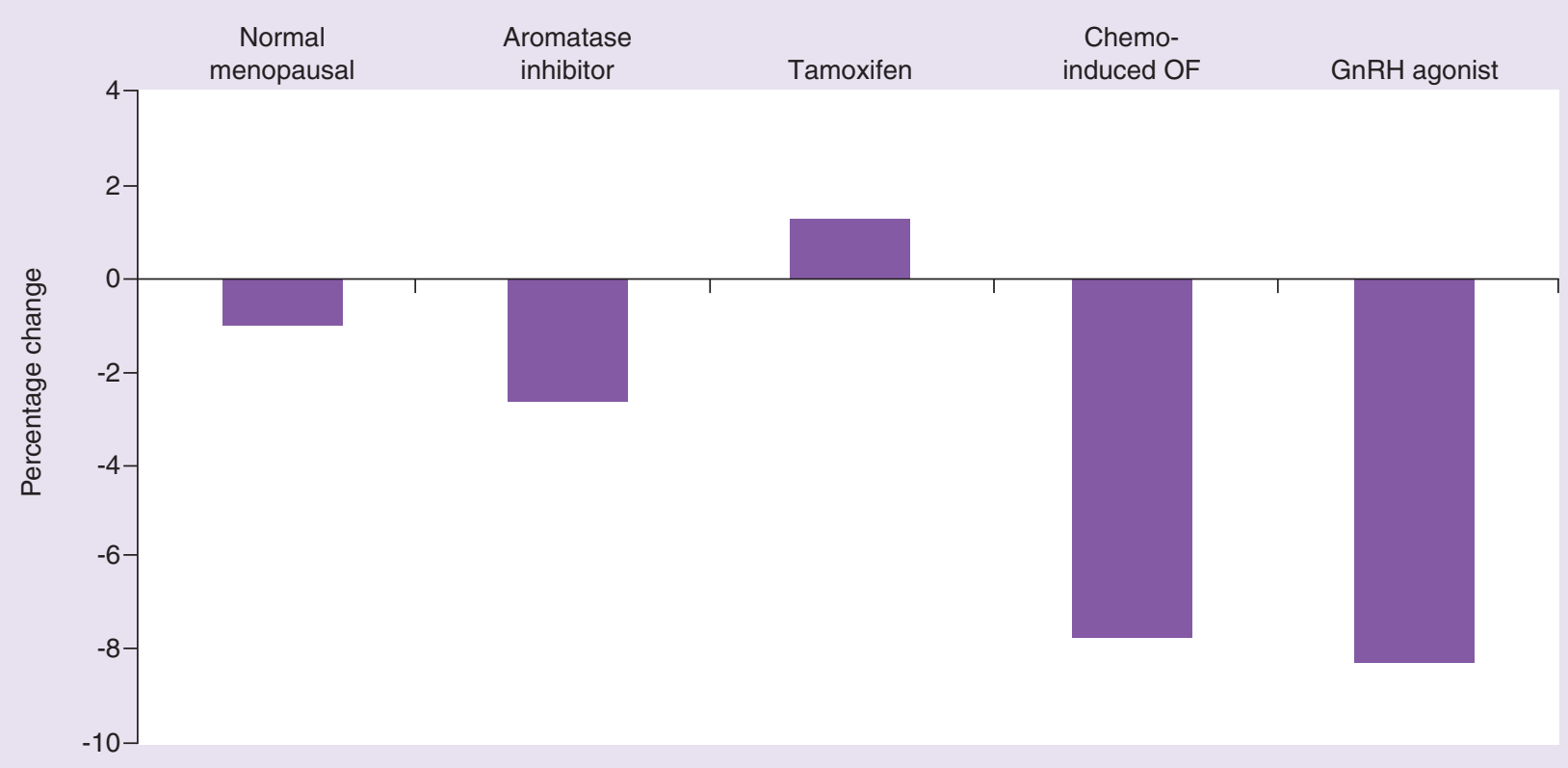

Figure 2. Percentage change in bone mineral density loss in spine at 12 months with various breast cancer treatments (Created by CLS). OF: Ovarian failure.

\section{Joint European: Al-bone loss: 2017}

Patient receiving $\mathrm{Al}, \mathrm{GnRH}$ agonist (or TAM in premenopausal women)

Exercise, calcium and vit D3

BMD of L/S spine, hip, FN by DEXA scan

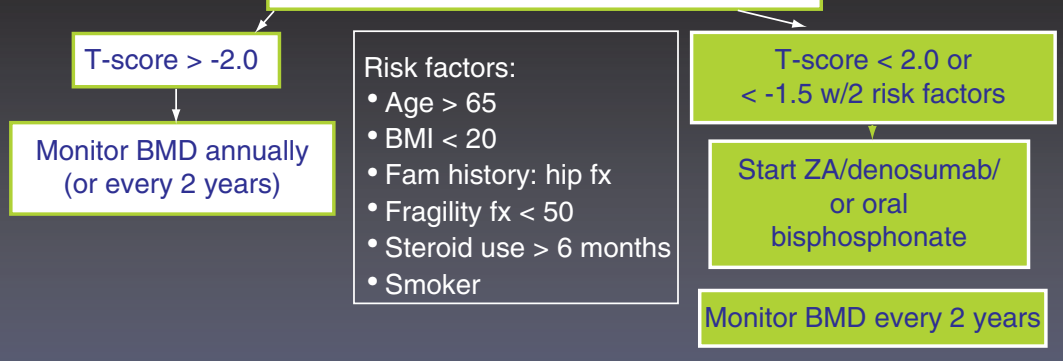

Figure 3. Suggested approach of aromatase inhibitor bone loss: Joint European Guidelines 2017.

Al: Aromatase inhibitor; BMD: Bone mineral density; FN: Femoral neck; Fx: Fracture; L/S: Lumbar spine; TAM: Tamoxifen; ZA: Zoledronic acid.

Used with permission from J. Bone Oncology [53]. 
fractures. However, the literature on this topic is conflicting based on studies that use different methodologies, sample sizes, populations and other factors. A review article concluded "... there are no strong associations between functional SNPs and AI-related adverse events with clinical implications" [18].

\section{GnRH antagonist, oophorectomy \& CIOF}

Treatment with a GnRH agonist (or antagonist) causes 'chemical menopause', is often combined with tamoxifen or AI $[19,20]$, and causes bone loss. Treatment with adjuvant chemotherapy leads to primary ovarian failure, which in turn leads to rapid bone loss that occurs as early as 6 months after the initiation of treatment and further increases at 12 months [21]. Figure 3 illustrates the magnitude of the bone loss $\mathrm{GnRH}$ agonist and CIOF with the percentage loss is $6-8 \%$ in the lumbar spine $[21,22]$.

The effect of chemotherapy on ovarian function depends on the age at treatment, the specific class of drug and the cumulative dose. The risk of CIOF increases with age because of the diminished ovarian reserve related to a reduction in the number and quality of follicles [23]. Alkylating agents, such as cyclophosphamide, are associated with the highest risk of CIOF [21], followed by platinum agents, anthracyclines and taxanes. Higher cumulative doses of cyclophosphamide associate with increases in the risk of CIOF. It is important to remember that transient amenorrhea may occur after chemotherapy with the resumption of menses. In women who retain menstrual function after chemotherapy, natural menopause can occur at earlier ages than in those who did not receive chemotherapy [24].

\section{Selective estrogen receptor modulators}

Both tamoxifen and raloxifene are selective estrogen receptor modulators. Selective estrogen receptor modulators bind to the estrogen receptor (ER), and depending on the target tissue acts as an estrogen agonist or antagonist [25]. In preclinical models, tamoxifen is an estrogen agonist in the bone. However, tamoxifen causes a small amount of bone loss in premenopausal women, whereas it mitigates bone loss in postmenopausal women (Figure 3) [26]. The bone-protecting properties of tamoxifen are relatively weak based on the finding that fragility fractures are not less frequent in women treated with tamoxifen [27]. Raloxifene, an US FDA approved drug for osteoporosis and prevention of breast cancer, increases BMD and decreases spine fractures but has no impact on non-spinal fractures [28]. There are more potent and effective drugs for treating osteoporosis in women with early-stage breast cancer.

\section{Aromatase inhibitors}

Anastrozole, exemestane and letrozole are the three selective AIs in use for the treatment of postmenopausal women with breast cancers expressing the estrogen receptor and or the progesterone receptor. Women that are receiving AI lose about 2-3\% of lumbar spine BMD (Figure 3) [29]. Aromatase (CYP19) a cytochrome P450 enzyme that converts adrenal gland-derived androgens to estrogens in postmenopausal women [30]. Many tissues, including ovarian, adipose, bone, healthy breast, breast cancer and brain, contain CYP19. Inhibiting aromatase results in decreasing estrogen levels lower than the already low estrogen levels of postmenopausal women [31]. Randomized trials and meta-analysis show the superiority of AIs over tamoxifen in disease-free and overall survival [32,33]. Women with breast cancer receiving AIs relative to tamoxifen [34] have higher fracture rates in randomized trials (Table 1), and in one large recent retrospective study women receiving AIs and bisphosphonates had lower risk of fractures [35]. The fracture risk remains elevated during the 5 years of AI treatment and decreases to the same rate as tamoxifen-treated women during years 5-10 [32].

\section{Screening \& risk factor assessment}

The central dual-energy $\mathrm{x}$-ray absorptiometry (DXA) scans measuring the total spine, hip and femoral neck [30] is the best screening test for osteoporosis. The T-score predicts fracture risk [41] and is the most important outcome variable of the DXA scan. The T-score is the number of standard deviations (SDs) the BMD falls above or below the mean peak BMD for a reference population of healthy 20-29-year-old females. For every 1 SD decrease in T-score, the risk of fracture increases about 1.5-2.5-fold. According to the WHO (Geneva, Switzerland), a normal T-score as -1.0 or above, a T-score between -1 and -2.5 is osteopenia, and a T-score below -2.5 or a non-traumatic fracture is osteoporosis [42]. The Z score, another outcome variable of the DXA scan, is the number of SDs that fall above or below that of the reference population of the same age and sex. The Z-score is useful for identifying potential secondary causes of osteoporosis. 


\begin{tabular}{|c|c|c|c|c|c|c|}
\hline Trial & $\mathbf{n}$ & $\begin{array}{l}\text { Follow-up } \\
\text { (months) }\end{array}$ & Treatment & Fractures (\%) & p-value & Ref. \\
\hline \multicolumn{7}{|l|}{ Al vs TAM } \\
\hline - ATAC & 9366 & 100 & ANA vs TAM & 11.0 vs 7.7 & $<0.001$ & [36] \\
\hline - BIG 1-98 & 4922 & 60 & LET vs TAM & 9.3 vs 6.5 & 0.002 & [37] \\
\hline \multicolumn{7}{|c|}{ Al after 2-3 years of TAM } \\
\hline - TEAM & 9779 & 61 & EXE vs TAM & 5.0 vs 3.0 & 0.0001 & [38] \\
\hline - ABCSG8/ARNO & 3224 & 28 & ANA vs TAM & 2.0 vs 1.0 & 0.015 & [39] \\
\hline \multicolumn{7}{|c|}{ Al after 5 years of TAM } \\
\hline - MA-17 & 5187 & 63 & LET vs placebo & 5.2 vs 3.1 & 0.02 & [40] \\
\hline
\end{tabular}

Al: Aromatase inhibitor; ANA: Anastrozole; EXE: Exemestane; LET: Letrozole; TAM: Tamoxifen.

Women initiating AI treatment should receive a baseline DXA scan. Counseling of women about modifiable risk factors that not only affect bone health but also influence overall health (e.g., reducing smoking, reducing alcohol consumption and increasing physical activity). Routinely checking vitamin 25-OH D levels is controversial. Vitamin D deficiency and insufficiency are prevalent among the general population and in women with breast cancer [43-45], especially in minority populations. Some healthcare providers routinely check a serum 25-OH vitamin D level before starting AIs. Others (including the author), use the initial DXA scan as a guide, checking serum $25-\mathrm{OH}$ vitamin $\mathrm{D}$ if osteopenia or osteoporosis is present.

\section{Supplemental calcium \& vitamin D}

Supplementing calcium and vitamin D will serve to decrease non-traumatic fractures in postmenopausal women with or without osteoporosis is controversial [42]. A Cochrane review concludes that vitamin D alone does not have an impact on fractures [46]. Supplementing calcium and vitamin D does lead to a small, statistically significant decrease in risk of the hip but not vertebral fractures. However, this is dependent on the setting (outpatient vs institutionalized population) and the underlying risk of osteoporosis (low vs high). There is evidence that supplemental calcium and vitamin D decrease postmenopausal BMD loss [42]. Furthermore, calcium and vitamin D supplementation prevents falls by affecting muscle strength [47-49], which, in turn, reduces fractures in an aging population.

Few trials evaluate the impact of calcium and vitamin D supplementation in cancer treatment-induced bone loss or women receiving AI. Of those that did, the consensus is that supplemental calcium and vitamin D of 500$1500 \mathrm{mg}$ and 200-1000 IU, respectively, do not prevent loss of BMD but mitigate it [50]. There is a broad consensus of the National Osteoporosis Foundation (VA, USA), National Academy of Sciences, Institute of Medicine (both Washington DC, USA) and US Preventive Services Task Force (MD, USA) that women over age 50 years should receive 1000-1200 $\mathrm{mg}$ of calcium (including dietary calcium) and 800-1000 IU vitamin D3 (cholecalciferol) daily [42]. In addition to reducing BMD loss, there is evidence to support other positive health outcomes, including cancer prevention [51]. Several position papers on AI-induced bone loss recommend these doses of calcium and vitamin D supplementation [52,53].

\section{Assessing fracture risk}

One the main risk factors for AI-induced fractures is having osteopenia or osteoporosis at the initiation of an AI [54]. The fracture risk assessment $\left(\mathrm{FRAX}^{\circledR}\right)$ calculator is used to estimate the 10-year risk of hip and non-hip vertebral fractures $[8,55,56]$. FRAX ${ }^{\circledR}$ uses the age, height, weight, sex and a variety of other risk factors (i.e., prior fracture, parental hip fracture, current smoking, glucocorticoids, rheumatoid arthritis, secondary osteoporosis, alcohol of three or more drinks per day and optional femoral neck T-score of BMD) [57]. The FRAX ${ }^{\circledR}$ calculator estimates the absolute 10-year risk of hip or non-hip fractures, but also the age-related thresholds for treating or not treating with anti-resorptive drugs. There are versions of FRAX ${ }^{\circledR}$ specific for each country.

The major European guideline groups published a consensus statement on the management of AI-induced bone loss [53]. In the guideline consensus paper, $\mathrm{FRAX}^{\circledR}$ may underestimate the 10-year fracture risk in women receiving AIs, and the authors provide an algorithm for using anti-resorptive drugs that does not involve FRAX $^{\circledR}$ (Figure 3) [53]. The European guideline contrasts with National Comprehensive Cancer Center Network (NCCN) 
Table 2. Major differences between zoledronic acid and denosumab.

\begin{tabular}{|c|c|c|}
\hline Factor & ZA (iv.) & Denosumab (sc.) \\
\hline Dose & $4 \mathrm{mg}$ & $60 \mathrm{mg}$ \\
\hline Mechanism & Osteoclast inhibitor & RANKL monoclonal antibody \\
\hline Metabolism & Not metabolized & Not metabolized \\
\hline Half-life & $\begin{array}{l}188 \text { days } \\
\text { (The majority } \\
\text { goes to bone) }\end{array}$ & 28 days \\
\hline Clearance & $\begin{array}{l}\text { Renal ( } 44 \% \text { of the dose excreted in urine within } 24 \mathrm{~h} \\
\text { after administration) }\end{array}$ & $\begin{array}{l}\text { The reticuloendothelial system most likely clears } \\
\text { denosumab with minimal renal filtration and excretion }\end{array}$ \\
\hline Common side effects & $\begin{array}{l}\text { Fever and chills; muscle, bone or joint pain; nausea; } \\
\text { fatigue and headache }\end{array}$ & Joint, muscle pains and hypocalcemia \\
\hline Rare side effects & Renal insufficiency and osteonecrosis & Osteonecrosis \\
\hline Cost $(\$)^{\dagger}(61)$ & 252.00 & 1906.00 \\
\hline
\end{tabular}

recommendations that suggest using FRAX $^{\circledR}$ to estimate risks of hip and nonhip fractures [58]. The recent ASCO guidelines on osteoporosis in the adult cancer survivor [59], recommends FRAX ${ }^{\circledR}$ in women treated with AIs designating them as having 'secondary osteoporosis' on the calculator. The designation of 'secondary osteoporosis' for women on AI when using FRAX ${ }^{\circledR}$ is called into question by a recent registry-based cohort study [60]. The results in the registry-based study suggest using 'secondary osteoporosis' for women receiving AIs overestimates the fracture risk.

The keys points of the recent ASCO guideline algorithm are assess underlying risk factors for osteoporosis (i.e., parental history of non-traumatic fracture, low body weight [under $150 \mathrm{lbs}$.], rheumatoid arthritis and diabetes); counseling about making lifestyle changes (i.e., reducing [or ceasing] cigarette and alcohol consumption, increasing physical activity, including weight-bearing activities and minimizing the risks of falling); taking adequate amounts of calcium (1000-1200 mg/day including dietary sources) and vitamin D3 (800-1000 IU/day); performing a DXA scan once every 2 years; and depending on the T-score, risk factors for osteoporosis and the FRAX ${ }^{\circledR}$ identifying a 10-year risk of hip and nonhip (vertebral) fracture that exceeds 3 or $20 \%$, respectively, initiate anti-osteoporosis drug after a dental screening exam [61]. Despite these guideline recommendations and attempts to promulgate them, compliance with recommendations is less than desired $[62,63]$.

\section{Prevention \& treatment with anti-osteoporosis drugs to prevent fractures in women with breast cancer}

Drugs for osteoporosis receive FDA approval based upon a reduction in fractures. Most studies of women with breast cancer use a surrogate end point for the fractures, the BMD, as the primary end point and to make decisions about when to institute antiresorptive treatment. The trials of anti-osteoporosis drugs are not large enough, and follow-up is too short to detect a reduction in fractures as a primary end point in women with breast cancer. The one exception that had as a primary end point a reduction in fractures was the Austrian Breast Cancer Study Group (ABCSG) trial 18. ABCSG trial 18 was a double-blind, placebo-controlled trial of denosumab/placebo in 3425 postmenopausal women receiving an AI. The primary end point was a reduction in fractures. The hazard rate (HR) for the reduction in fractures was 0.50 (95\% CI: 0.39-0.65). An update of the randomized-open label AZURE trial with 84 months of follow-up showed 5-year fracture rate of 3.8\% (95\% CI: 2.9-4.7\%) for zoledronic acid (ZA) group and 5.9\% (95\% CI: 4.8-7.1\%) in the control group [64].

The osteoclast inhibitor, ZA and the RANKL inhibitor, denosumab (Figure 1), are drugs used to mitigate BMD loss in women developing CIOF or receiving AIs. Table 2 describes ZA and denosumab. The primary differences in these drugs are in their mechanism of action, routes of administration, toxicities and the cost [65]. There are no randomized trials directly comparing ZA and denosumab to mitigate BMD loss in women treated with AIs. In $\mathrm{CIOF}$ or $\mathrm{GnRH}$ agonist treatment, ZA prevents bone loss [22,66,67], and likewise, in AI-induced bone loss ZA $[19,68,69]$ and denosumab $[70,71]$ also prevent bone loss (Table 3 ).

Instructive is the results of the ZO-Fast trial [69]. Over 1000 postmenopausal women receiving letrozole $2.5 \mathrm{mg}$ a day were randomized to either immediate ZA $4 \mathrm{mg}$ intravenous every 6 months for 5 years or to receive ZA only 


\begin{tabular}{|c|c|c|c|c|c|}
\hline Trial & Treatments & $\mathbf{n}$ & Results & p-value & Ref. \\
\hline \multicolumn{6}{|l|}{ CIOF } \\
\hline - Hershman 2008 & ZA 4 mg q3 months vs placebo for 1 year & 101 & L/S BMD 0\% ZA vs $-3.0 \%$ placebo & $<0.001$ & [67] \\
\hline - Shapiro 2011 & ZA 4 mg q3 months vs control for 1 year & 441 & L/S BMD $1.2 \%$ ZA vs $-6.7 \%$ controls & $<0.001$ & [22] \\
\hline \multicolumn{6}{|l|}{ - GnRH agonist } \\
\hline - Gnant 2008 & ZA 4 mg q6 months for 3 years vs control & 404 & $\begin{array}{l}\text { L/S BMD } 4.0 \% \text { ZA vs baseline } \\
\text { L/S BMD }-6.7 \% \text { vs baseline }\end{array}$ & $\begin{array}{l}0.02 \\
0.001\end{array}$ & [19] \\
\hline \multicolumn{6}{|l|}{$\mathrm{Al}$} \\
\hline - Brufsky 2007 & $\begin{array}{l}\text { ZA } 4 \text { mg q6 months for } 5 \text { years vs delayed } \\
\text { ZA }\end{array}$ & 602 & L/S BMD $4.4 \%$ vs delayed & $<0.001$ & [68] \\
\hline - Coleman 2013 & $\begin{array}{l}\text { ZA } 4 \text { mg q6 months for } 5 \text { years vs delayed } \\
\text { ZA }\end{array}$ & 1065 & L/S BMD $5.7 \%$ vs delayed & $<0.001$ & [69] \\
\hline - Ellis 2008 & $\begin{array}{l}\text { Denosumab q6 months for } 2 \text { years vs } \\
\text { placebo }\end{array}$ & 282 & L/S BMD $5.5 \%$ vs placebo & $<0.001$ & [71] \\
\hline - Gnant 2015 & $\begin{array}{l}\text { Denosumab q6 months for } 5 \text { years vs } \\
\text { placebo }\end{array}$ & 3425 & $\begin{array}{l}\text { Fractures in denosumab group } 92, \text { placebo } \\
176 \\
H R=0.50 ; 95 \% \mathrm{Cl}: 0.39-0.65\end{array}$ & $<0.0001$ & [70] \\
\hline
\end{tabular}

Al: Aromatase inhibitor; CIOF: Chemotherapy-induced ovarian failure; GnRH: Gonadotropin-releasing hormone antagonist; HR: Hazard rate; L/S: Lumbar spine; ZA: Zoledronic acid.

if the DXA showed a decreasing T-score of less than or equal to minus 2.0, or an osteoporotic fracture occurred. Entry criteria included those women with normal BMD (i.e., T-scores of -1.0 or above) or osteopenia with T-scores of -1.0 to -2.0 . As expected, the group that was randomized to immediate ZA statistically significantly increased BMD in lumbar while the delayed ZA group lost bone. However, after 5 years, only $27 \%$ of the delayed ZA group received ZA. Thus, only a minority of women on AIs needed antiresorptive drugs, at least for the first 5 years.

\section{Antiresorptive drugs as anticancer drugs}

Several randomized trials [70,72,73] and a recent meta-analysis [74] suggest that in postmenopausal women or premenopausal women rendered postmenopausal with a GnRH antagonist [75] principally ZA and other oral bisphosphonates including clodronate (not available in the USA) and risedronate, improve clinical outcomes such as bone recurrence and cancer deaths. Included in the meta-analysis were over 11,000 postmenopausal and over 6000 premenopausal early-stage women with breast cancer. In the postmenopausal women only, the 10-year absolute decreases in bone recurrence, and cancer mortality were $2.2 \%(\mathrm{p}=0.0002)$ and $3.3 \%(\mathrm{p}=0.002)$, respectively. In 2017, the Canadian Care Ontario and American Society of Clinical Oncology Clinical Practice Guidelines Focused Update put out a statement on the use of adjuvant antiresorptive drugs. The guideline stated 'consider' ZA (4 mg iv.) every 6 months for three to 5 years or oral clodronate $1600 \mathrm{mg}$ per day (only available in Europe) for 3 years in high-risk postmenopausal women [76]. Additional clinical trials of antiresorptive drugs, specifically in early-stage postmenopausal women, are needed to confirm the evidence of the meta-analysis [77].

In trial ABCSG trial 18 [70], between denosumab and placebo there were no differences in histologically verified invasive local-regional recurrences, distant recurrences, contralateral new primary cancers or ductal carcinoma in situ. The superior disease-free survival in the denosumab-treated women was in the non-histologically verified distant metastases or new primary breast cancers. One could argue that the double-blind, placebo-controlled design and the intention-to-treat analysis, would minimize bias. Despite sensitivity analyses that accounted for bias, possibly chance or unknown imbalances existed to make the numbers of histologically unverified new primary breast cancers (100 vs 80$)$ and distant recurrences (68 vs 56) higher in placebo-treated patients.

The randomized-placebo controlled D-CARE enrolled 4509, women [78]. The primary end point, bone recurrences was not different for denosumab and placebo groups with the hazard ratio (HR) 0.97 (95\% CI: $0.82-1.14), \mathrm{p}=0.70$, and the secondary end point, disease-free survival was not different (HR: 1.04; $95 \% \mathrm{CI}$ : $0.91-1.19 ; \mathrm{p}=0.57)$. They presented the results of a preplanned subset analysis, and there were no differences by menopausal status. With the uncertainties of ABCSG trial 18 and wholly negative D-CARE trial, denosumab should not be used as an anticancer drug at this time. 


\section{Conclusion}

The majority of breast cancer survivors are their sixth, seventh and eighth decades and osteoporosis is a disease of aging. As such, the screening and treatment of osteoporosis in women with breast cancer is a high priority. Despite guidelines and algorithms, compliance with screening and treatment recommendations is poor [62]. The American Society of Clinical Oncology (www.asco.org) and the Quality Practice Initiative Program [79] sponsors various efforts to promote guideline adherence. It is important to identify for the individual woman the provider charged with taking responsibility for bone health (e.g., the primary care physician, the oncologist, the obstetric and gynecologist, the endocrinologist, or the rheumatologist), varying with local expertise and practice patterns. Lifestyle changes that promote bone health (e.g., stopping or reducing smoking and drinking, and increasing physical activity, especially weight-bearing exercises) promote overall health. Nontraumatic hip and vertebral fractures cause morbidity and mortality [80]. Unlike other chronic diseases, the first symptom of osteoporosis is often fracture, emphasizing the imperative that women with early breast cancer, whose treatments lose bone, are screened and appropriately treated for osteoporosis.

\section{Future perspective}

A newer drug such as the monoclonal antibody rosmosozumab [81] is FDA-approved for postmenopausal women and will require testing in women with breast cancer. It is important to compare not only the therapeutic ratio of rosmosozumab to ZA or denosumab but also the cost-effectiveness. Bisphosphonates as anticancer drugs is an exciting prospect, yet only about $40 \%$ of oncologists use it currently in their 'high risk' postmenopausal women [82]. It is uncertain whether additional trials of ZA as an anticancer drug will occur.

Financial \& competing interests disclosure

The authors have no relevant affiliations or financial involvement with any organization or entity with a financial interest in or financial conflict with the subject matter or materials discussed in the manuscript. This includes employment, consultancies, honoraria, stock ownership or options, expert testimony, grants or patents received or pending, or royalties.

No writing assistance was utilized in the production of this manuscript.

Open access

This work is licensed under the Attribution-NonCommercial-NoDerivatives 4.0 Unported License. To view a copy of this license, visit http://creativecommons.org/licenses/by-nc-nd/4.0/

\section{References}

1. Binbing Y, Tiwari RC, Feuer EJ. Estimating the personal cure rate of cancer patients using population-based grouped cancer survival data. Stat. Methods Med. Res. 20(3), 261-274 (2011).

2. Shapiro CL, Jacobsen PB, Henderson T et al. ReCAP: ASCO core curriculum for cancer survivorship education. J. Oncol. Pract. 12(2), 145 (2016).

3. Bluethmann SM, Mariotto AB, Rowland JH. Anticipating the "Silver Tsunami": prevalence trajectories and comorbidity burden among older cancer survivors in the United States. Cancer Epidemiol. Biomarkers Prev. 25(7), 1029-1036 (2016).

4. Boyle WJ, Simonet WS, Lacey DL. Osteoclast differentiation and activation. Nature 423(6937), 337-342 (2003).

5. Weitzmann MN, Pacifici R. T cells: unexpected players in the bone loss induced by estrogen deficiency and in basal bone homeostasis. Ann. NY Acad. Sci. 1116(1), 360-375 (2007).

6. D'Amelio P, Grimaldi A, Di Bella $S$ et al. Estrogen deficiency increases osteoclastogenesis up-regulating T cells activity: a key mechanism in osteoporosis. Bone 43(1), 92-100 (2008).

7. Ramaswamy B, Shapiro CL. Osteopenia and osteoporosis in women with breast cancer. Semin. Oncol. 30(6), 763-775 (2003).

8. Kanis JA, Cooper C, Rizzoli R et al. European guidance for the diagnosis and management of osteoporosis in postmenopausal women. Osteoporos. Int. 30(1), 23-57 (2013).

9. Warming L, Hassager C, Christiansen C. Changes in bone mineral density with age in men and women: a longitudinal study. Osteoporos. Int. 13(2), 105-112 (2002).

10. Hsu YH, Estrada K, Evangelou $\mathrm{E}$ et al. Meta-analysis of genomewide association studies reveals genetic variants for hip bone geometry. $J$. Bone Miner. Res. 34(7), 1284-1296 (2019).

11. Morris JA, Kemp JP, Youlten SE et al. An atlas of genetic influences on osteoporosis in humans and mice. Nat. Genet. 51(2), 258-266 (2019). 
12. Kemp JP, Morris JA, Medina-Gomez C et al. Identification of 153 new loci associated with heel bone mineral density and functional involvement of GPC6 in osteoporosis. Nat. Genet. 49(10), 1468-1475 (2017).

13. Liu M, Goss PE, Ingle JN et al. Aromatase inhibitor-associated bone fractures: a case-cohort GWAS and functional genomics. Mol. Endocrinol. 28(10), 1740-1751 (2014).

14. Artigalas O, Vanni T, Hutz MH, Ashton-Prolla P, Schwartz IV. Influence of CYP19A1 polymorphisms on the treatment of breast cancer with aromatase inhibitors: a systematic review and meta-analysis. BMC Med. 13, 139 (2015).

15. Napoli N, Rastelli A, Ma C et al. Genetic polymorphism at Val80 (rs700518) of the CYP19A1 gene is associated with aromatase inhibitor associated bone loss in women with ER + breast cancer. Bone 55(2), 309-314 (2013).

16. Oesterreich S, Henry NL, Kidwell KM et al. Associations between genetic variants and the effect of letrozole and exemestane on bone mass and bone turnover. Breast Cancer Res. Treat. 154(2), 263-273 (2015).

17. Rodriguez-Sanz M, García-Giralt N, Prieto-Alhambra D et al. CYP11A1 expression in bone is associated with aromatase inhibitor-related bone loss. J. Mol. Endocrinol. 55(1), 69-79 (2015).

18. Sini V, Botticelli A, Lunardi G, Gori S, Marchetti P. Pharmacogenetics and aromatase inhibitor induced side effects in breast cancer patients. Pharmacogenomics 18(8), 821-830 (2017).

19. Gnant M, Mlineritsch B, Luschin-Ebengreuth G et al. Adjuvant endocrine therapy plus zoledronic acid in premenopausal women with early-stage breast cancer: 5-year follow-up of the ABCSG-12 bone-mineral density substudy. Lancet Oncol. 9(9), 840-849 (2008).

20. Fogelman I, Blake GM, Blamey R et al. Bone mineral density in premenopausal women treated for node-positive early breast cancer with 2 years of goserelin or 6 months of cyclophosphamide, methotrexate and 5-fluorouracil (CMF). Osteoporos. Int. 14(2), 1001-1006 (2003).

21. Shapiro CL, Manola J, Leboff M. Ovarian failure after adjuvant chemotherapy is associated with rapid bone loss in women with early-stage breast cancer. J. Clin. Oncol. 19(14), 3306-3311 (2001).

22. Shapiro CL, Halabi S, Hars V et al. Zoledronic acid preserves bone mineral density in premenopausal women who develop ovarian failure due to adjuvant chemotherapy: final results from CALGB trial 79809. Eur. J. Cancer 47(5), 683-689 (2011).

23. Gracia CR, Sammel MD, Freeman E et al. Impact of cancer therapies on ovarian reserve. Fertil. Steril. 97(1), 134-140 (2012).

24. Partridge A Gelber S, Gelber RD, Castiglione-Gertsch M, Goldhirsch A, Winer E. Age of menopause among women who remain premenopausal following treatment for early breast cancer: long-term results from International Breast Cancer Study Group Trials V and VI. Eur. J. Cancer 43(11), 1646-1653 (2007).

25. Fontana A, Delmas PD. Selective estrogen receptors modulators in the prevention and treatment of postmenopausal osteoporosis. Endocrinol. Metab. Clin. North Am. 32(1), 219-232 (2003).

26. Powles TJ, Hickish T, Kanis JA, Tidy A, Ashley S. Effect of tamoxifen on bone mineral density measured by dual-energy x-ray absorptiometry in healthy premenopausal and postmenopausal women. J. Clin. Oncol. 14(1), 78-84 (1996).

27. Kristensen B, Ejlertsen B, Mouridsen HT, Andersen KW, Lauritzen JB. Femoral fractures in postmenopausal breast cancer patients treated with adjuvant tamoxifen. Breast Cancer Res. Treat. 39(3), 321-326 (1996).

28. Ensrud KE, Stock JL, Barrett-Connor E et al. Effects of raloxifene on fracture risk in postmenopausal women: the raloxifene use for the heart trial. J. Bone Miner. Res. 23(1), 112-120 (2008).

29. Eastell R, Hannon RA, Cuzick J et al. Effect of an aromatase inhibitor on bmd and bone turnover markers: 2-year results of the Anastrozole, Tamoxifen, Alone or in Combination (ATAC) trial (18233230). J. Bone Miner. Res. 21(8), 1215-1223 (2006).

30. Pant S1, Shapiro CL. Aromatase inhibitor-associated bone loss: clinical considerations. Drugs 68(18), 2591-2600 (2008).

31. Lønning PE, Eikesdal HP. Aromatase inhibition 2013: clinical state of the art and questions that remain to be solved. Endocr. Relat. Cancer 20(4), 183-201 (2013).

32. Cuzick J, Sestak I, Baum M et al. Effect of anastrozole and tamoxifen as adjuvant treatment for early-stage breast cancer: 10-year analysis of the ATAC trial. Lancet Oncol. 11(12), 1135-1141 (2010).

33. Early Breast Cancer Trialists' Collaborative Group. Aromatase inhibitors versus tamoxifen in early breast cancer: patient-level meta-analysis of the randomised trials. Lancet 386(10001), 1341-1352 (2015).

34. Milat F, Vincent AJ. Management of bone disease in women after breast cancer. Climacteric 18(Suppl. 2), 47-55 (2015).

35. Pineda-Moncusí M, Garcia-Giralt N1, Diez-Perez A et al. Increased fracture risk in women treated with aromatase inhibitors versus tamoxifen: beneficial effect of bisphosphonates. J. Bone Miner. Res. 35(2), 291-297 (2020).

36. Howell A, Cuzick J, Baum M et al. Results of the ATAC (arimidex, tamoxifen, alone or in combination) trial after completion of 5 years' adjuvant treatment for breast cancer. Lancet 365(9453), 60-62 (2005).

37. Rabaglio M, Sun Z, Price KN et al. Bone fractures among postmenopausal patients with endocrine-responsive early breast cancer treated with 5 years of letrozole or tamoxifen in the BIG 1-98 trial. Ann. Oncol. 20(9), 1489-1498 (2009).

38. van de Velde CJ, Rea D, Seynaeve C et al. Adjuvant tamoxifen and exemestane in early breast cancer (TEAM): a randomised Phase III trial. Lancet 377(9762), 321-331 (2011). 
39. Jakesz R, Jonat W, Gnant M et al. Switching of postmenopausal women with endocrine-responsive early breast cancer to anastrozole after 2 years' adjuvant tamoxifen: combined results of ABCSG trial 8 and ARNO 95 trial. Lancet 366(9484), 455-462 (2005).

40. Goss PE, Ingle JN, Martino $S$ et al. Randomized trial of letrozole following tamoxifen as extended adjuvant therapy in receptor-positive breast cancer: updated findings from NCIC CTG MA.17. J. Natl Cancer Inst. 97(17), 1262-1271 (2005).

41. Cummings SR, Bates D, Black DM. Clinical use of bone densitometry: scientific review. JAMA 288(15), 1889-1897 (2002).

42. Kling JM, Clarke BL, Sandhu NP. Osteoporosis prevention, screening, and treatment: a review. J. Womens Health 23(7), 563-572 (2014).

43. Forrest KY, Stuhldreher WL. Prevalence and correlates of vitamin D deficiency in US adults. Nutr. Res. 31(1), 48-54 (2011).

44. Friedman CF, DeMichele A, Su HI et al. Vitamin D deficiency in postmenopausal breast cancer survivors. J. Womens Health 21(4), 456-462 (2012).

45. Nogues X, Servitja S, Реп̆а MJ et al. Vitamin D deficiency and bone mineral density in postmenopausal women receiving aromatase inhibitors for early breast cancer. Maturitas 66(3), 291-297 (2010).

46. Avenell A, Mak JC, O'Connell D. Vitamin D and vitamin D analogues for preventing fractures in post-menopausal women and older men. Cochrane Database Syst. Rev. 14(4), CD000227 (2014).

47. Wu H, Pang Q. The effect of vitamin D and calcium supplementation on falls in older adults: a systematic review and meta-analysis. Orthopade 46(9), 729-736 (2017).

48. Dawson-Hughes B. Vitamin D and muscle function. J. Steroid Biochem. Mol. Biol. 173, 313-316 (2017)

49. Dhaliwal R, Aloia JF. Effect of vitamin D on falls and physical performance. Endocrinol. Metab. Clin. North Am. 46(4), 919-933 (2017).

50. Datta M, Schwartz GG. Calcium and vitamin D supplementation and loss of bone mineral density in women undergoing breast cancer therapy. Crit. Rev. Oncol. Hematol. 88(3), 613-624 (2013).

51. Jeon SM, Shin EA. Exploring vitamin D metabolism and function in cancer. Exp. Mol. Med. 50(4), 20 (2018).

52. Trémollieres FA, Ceausu I, Depypere $\mathrm{H}$ et al. Osteoporosis management in patients with breast cancer: EMAS position statement. Maturitas 95, 65-71 (2017).

53. Hadji P, Aapro MS, Body JJ et al. Management of Aromatase Inhibitor-Associated Bone Loss (AIBL) in postmenopausal women with hormone sensitive breast cancer: joint position statement of the IOF, CABS, ECTS, IEG, ESCEO IMS, and SIOG. J. Bone Oncol. 7 , $1-12$ (2017).

54. García-Giralt N, Pineda-Moncusí M, Ovejero D et al. Risk factors for Incident fracture in patients with breast cancer treated with aromatase inhibitors: b-ABLE cohort. Rev. Osteoporos. Metab. Miner. 12(1), 1-7 (2020).

55. Kanis JA, McCloskey EV, Johansson H, Oden A, Ström O, Borgström F. Development and use of FRAX in osteoporosis. Osteoporos. Int. 21(Suppl. 2), 407-413 (2010).

56. The University of Sheffield. FRAX: fracture risk assessment tool. http://www.sheffield.ac.uk/FRAX/

57. Leslie WD, Majumdar SR, Lix LM et al. High fracture probability with FRAX usually indicates densitometric osteoporosis: implications for clinical practice. Osteoporos. Int. 23(1), 391-397 (2012).

58. Gralow JR, Biermann JS, Farooki A et al. NCCN task force report: bone health in cancer care. J. Natl Compr. Canc. Netw. 11(Suppl. 3), S1-S50 (2013).

59. Shapiro CL, Van Poznak C, Lacchetti C et al. Management of osteoporosis in survivors of adult cancers with nonmetastatic disease: ASCO clinical practice guideline. J. Clin. Oncol. 37(31), 2916-2946 (2019).

60. Leslie WD, Morin SN, Lix LM et al. Performance of FRAX in women with breast cancer initiating aromatase inhibitor therapy: a registry-based cohort study. J. Bone Miner. Res. 34(8), 1428-1435 (2019).

61. Yarom N, Shapiro CL, Peterson DE et al. Medication-related osteonecrosis of the jaw: MASCC/ISOO/ASCO clinical practice guideline. J. Clin. Oncol. 37(25), 2270-2290 (2019).

62. Tremblay D, Patel V, Fifer KM et al. Management of bone health in postmenopausal women on aromatase inhibitors (AIs): a single health care system experience. Support. Care Cancer 26(1), 197-202 (2018).

63. Seeman E, Compston J, Adachi J et al. Non-compliance: the Achilles' heel of anti-fracture efficacy. Osteoporos. Int. 18(6), 711-719 (2007).

64. Wilson C, Bell R, Hinsley $S$ et al. Adjuvant zoledronic acid reduces fractures in breast cancer patients; an AZURE (BIG 01/04) study. Eur. J. Cancer 94, 70-78 (2018).

65. Shapiro CL, Moriarty JP, Dusetzina S et al. Cost-effectiveness analysis of monthly zoledronic acid, zoledronic acid every 3 months, and monthly denosumab in women with breast cancer and skeletal metastases: CALGB 70604 (Alliance). J. Clin. Oncol. 35(35), 3949-3955 (2017).

66. Gnant MF, Mlineritsch B, Luschin-Ebengreuth G et al. Zoledronic acid prevents cancer treatment-induced bone loss in premenopausal women receiving adjuvant endocrine therapy for hormone-responsive breast cancer: a report from the Austrian Breast and Colorectal Cancer Study Group. J. Clin. Oncol. 25(7), 820-828 (2007). 
67. Hershman DL, McMahon DJ, Crew KD et al. Zoledronic acid prevents bone loss in premenopausal women undergoing adjuvant chemotherapy for early-stage breast cancer. J. Clin. Oncol. 26(29), 4739-4745 (2008).

68. Brufsky A, Harker WG, Beck JT et al. Zoledronic acid inhibits adjuvant letrozole-induced bone loss in postmenopausal women with early breast cancer. J. Clin. Oncol. 25(7), 829-836 (2007).

69. Coleman R, de Boer R, Eidtmann $\mathrm{H}$ et al. Zoledronic acid (zoledronate) for postmenopausal women with early breast cancer receiving adjuvant letrozole (ZO-FAST study): final 60-month results. Ann. Oncol. 24(2), 398-405 (2013).

70. Gnant M, Pfeiler G, Dubsky PC et al. Adjuvant denosumab in breast cancer (ABCSG-18): a multicentre, randomised, double-blind, placebo-controlled trial. Lancet 386(9992), 433-443 (2015).

71. Ellis GK, Bone HG, Chlebowski R et al. Randomized trial of denosumab in patients receiving adjuvant aromatase inhibitors for nonmetastatic breast cancer. J. Clin. Oncol. 26(30), 4875-4882 (2008).

72. Coleman RE, Marshall H, Cameron D et al. Breast-cancer adjuvant therapy with zoledronic acid. N. Engl. J. Med. 365(15), 1396-1405 (2011).

73. Paterson AH, Anderson SJ, Lembersky BC et al. Oral clodronate for adjuvant treatment of operable breast cancer (National Surgical Adjuvant Breast and Bowel Project protocol B-34): a multicentre, placebo-controlled, randomised trial. Lancet Oncol. 13(7), 734-742 (2012).

74. Early Breast Cancer Trialists' Collaborative Group. Adjuvant bisphosphonate treatment in early breast cancer: meta-analyses of individual patient data from randomised trials. Lancet 386(10001), 1353-1361 (2015).

75. Gnant M, Mlineritsch B, Stoeger $\mathrm{H}$ et al. Zoledronic acid combined with adjuvant endocrine therapy of tamoxifen versus anastrozol plus ovarian function suppression in premenopausal early breast cancer: final analysis of the Austrian Breast and Colorectal Cancer Study Group Trial 12. Ann. Oncol. 26(2), 313-320 (2015).

76. Dhesy-Thind S, Fletcher GG, Blanchette PS et al. Use of adjuvant bisphosphonates and other bone-modifying agents in breast cancer: a Cancer Care Ontario and American Society of Clinical Oncology Clinical Practice Guideline. J. Clin. Oncol. 35(18), 2062-2081 (2017).

77. O'Carrigan B, Wong MH, Willson ML, Stockler MR, Pavlakis N, Goodwin A. Bisphosphonates and other bone agents for breast cancer. Cochrane Database Syst. Rev. 10, CD003474 (2017).

78. Coleman R, Finkelstein DM, Barrios C et al. Adjuvant denosumab in early breast cancer (D-CARE): an international, multicentre, randomised, controlled, Phase III trial. Lancet Oncol. 21(1), 60-72 (2020).

79. Neuss MN, Desch CE, McNiff KK et al. A process for measuring the quality of cancer care: the quality oncology practice initiative. J. Clin. Oncol. 23(25), 6233-6239 (2005).

80. Morin S, Lix LM, Azimaee M, Metge C, Caetano P, Leslie WD. Mortality rates after incident non-traumatic fractures in older men and women. Osteoporos. Int. 22(9), 2439-2448 (2011).

81. Saag KG, Petersen J, Brandi ML et al. Romosozumab or alendronate for fracture prevention in women with osteoporosis. N. Engl. J. Med. 377(15), 1417-1427 (2017).

82. Balic M, Thomssen C, Wurstlein R, Gnant M, Harbeck N. St. Gallen/Vienna 2019: a brief summary of the consensus discussion on the optimal primary breast cancer treatment. Breast Care 14, 103-110 (2019). 